\title{
Longitudinal association of adiposity with wheezing and atopy at 22 years: the 1993 Birth Cohort, Pelotas, Brazil
}

This article was published in the following Dove Press journal: Journal of Asthma and Allergy

\author{
Ana Maria Baptista \\ Menezes' \\ Paula Duarte de Oliveira' \\ Cauane Blumenberg' \\ Efrain Sanchez-Angarita ${ }^{2}$ \\ Gloria Isabel Niño-Cruz' \\ Ignacio Zabert ${ }^{3}$ \\ Janaina Calu Costa' \\ Luiza Isnardi Cardoso \\ Ricardo' \\ Rafaela Costa Martins' \\ Fernando César \\ Wehrmeister ${ }^{\prime}$ \\ 'Postgraduate Program in \\ Epidemiology, Federal University of \\ Pelotas, Pelotas, RS, Brazil; ${ }^{2}$ Pulmonary \\ Department, Hospital Universitario \\ de Caracas, Universidad Central de \\ Venezuela, Capital District, Venezuela; \\ ${ }^{3}$ Facultad de Medicina, Universidad \\ Nacional del Comahue, Neuquén, \\ Argentina
}

Purpose: Asthma is a highly prevalent noncommunicable lung disease. The aim of this study was to evaluate the longitudinal association of obesity/adiposity with wheezing and atopy.

Methods: The population of the study was composed of participants from the 1993 Pelotas (Brazil) Birth Cohort. The following outcome variables were measured at 22 years: wheezing in the last 12 months, wheezing with atopy, wheezing without atopy, only atopy, and persistent wheezing at 18 and 22 years. Exposure variables were obesity body mass index, percent fat mass (FM), and fat mass index, which were obtained by precise methods (BOD POD and dualenergy X-ray absorptiometry [DXA]). Crude and adjusted logistic and multinomial logistic regressions were used in the analyses.

Results: The prevalence of wheezing (with and without atopy), wheezing without atopy, only atopy, and persistent wheezing were $10.6 \%, 3.9 \%, 30.9 \%$, and $4.0 \%$, respectively. To be obese or to belong to the highest tertile of obesity/adiposity at two follow-ups showed a cumulative and positive association with wheezing in the adjusted analysis; for atopy there was no significant association. The odds ratio (OR) for wheezing according to the percentage of total FM measured by DXA in the highest tertile at both follow-ups was 1.58 (95\% CI: 1.14-2.20) against an OR of 1.16 (95\% CI: 0.92-1.47) for atopy. Persistent wheezing was also associated with adiposity, but without statistical significance.

Conclusions: We found a positive longitudinal association between several measures of adiposity and wheezing at 22 years old. The effect was higher for cumulative adiposity; the results for atopy were not consistent.

Keywords: asthma, BMI, fat mass, fat mass index

\section{Background}

Most of the literature shows a direct association between asthma or wheezing and obesity. ${ }^{1-4}$ Two systematic reviews among children ${ }^{5,6}$ showed that overweight and obesity are associated with an increased risk of childhood asthma. Besides the systematic reviews among children, a systematic analysis among adults showed that asthma incidence increases by $50 \%$ in overweight/obese subjects with a dose-response relationship without effect of gender. ${ }^{7}$

Although there is almost a consensus about the association of asthma/wheezing Menezes

Postgraduate Program in Epidemiology, Federal University of Pelotas, Mal.

Deodoro, $1160,3^{\circ}$ andar, CEP: $96020-$

220, Pelotas, RS, Brazil

Tel/fax +55 533284 I 300

Email anamene.epi@gmail.com and obesity, few studies have explored the atopic and nonatopic phenotypes of asthma, and the results are not so consistent as the previous ones. In a systematic review for risk factors for nonatopic asthma/wheeze in children and adolescents, obesity was found to be a risk factor. ${ }^{8}$ However, the majority of the studies have used body mass 
index (BMI) or skinfolds as the main measure of obesity and these indicators are not the best methods for measuring fat mass (FM) or lean mass; it has been recognized that BMI does not reflect adiposity and the gold standard for adiposity is measured by dual-energy X-ray absorptiometry (DXA) or by BOD POD., 910

Most longitudinal studies on this subject have been carried out outside Latin America (LA), and it is plausible to think that findings in LA can be different from developed countries because the prevalence of atopy is very high in LA. ${ }^{11}$

Based on this, the aim of this paper was to measure the longitudinal association of obesity and adiposity measured by BMI, DXA, and BOD POD with three phenotypes of asthma: wheezing, atopy, and persistent wheezing, in a birth cohort from Southern Brazil, at the beginning of adulthood.

\section{Methods}

In 1993, all hospitals in the city of Pelotas were visited daily from 1 January to 31 December 1993. All mothers who had given birth at these institutions were invited to take part in the study and soon after delivery they were interviewed. ${ }^{12}$ From the 5,265 live births in the city, 5,249 were enrolled in our birth cohort study. Subsamples of the cohort were followed up during childhood, ${ }^{12}$ and all cohort members were sought when they had reached the mean age of $11,15,18$, and 22 years. ${ }^{13}$

The outcomes were defined according to the questionnaire of the "International Study of Asthma and Allergies in Childhood Steering Committee", which has already been validated in Brazil ${ }^{14,15}$ : a) presence of wheezing in the last year collected at 22 years, b) wheezing without atopy at 22 years, c) wheezing with atopy, and d) only atopy symptoms. The outcome "persistent wheezing" (presence of wheezing at 18 and at 22 years) was also analyzed and it has been shown as Table S1. Wheezing was treated as a binary variable and considered present after a positive answer to the following question: "Have you had wheezing or whistling in the chest in the past 12 months?". Atopy symptoms were assessed based on binary questions about rhinitis and eczema: 1) "In the last 12 months, have you had any problems with sneezing, runny nose, or stuffy nose without having a flu or a cold?"; 2) "Have you ever had itchy rash, which have appeared and disappeared for at least 6 months? 3) In the last 12 months, have you had these itchy rashes on your skin?"; If the participant answered yes for any of the three questions, we considered that he had atopy symptoms in the last year.

The main exposure variables, collected at 18 - and 22-year follow-ups, were BMI $\left(\mathrm{kg} / \mathrm{m}^{2}\right)$, percentage of total FM measured by the BOD POD (air displacement plethysmography - BOD POD ${ }^{\circledR}$ Composition System; COSMED, Albano Laziale, Italy), ${ }^{16}$ percentage of segmented (trunk) FM measured by DXA - model Lunar Prodigy Advance ${ }^{\circledR}$; GE Healthcare Europe GmbH, Freiburg, Germany), and fat mass index (FMI; fat kg [BOD POD]/ height $\mathrm{m}^{2}$ ). BMI was categorized as obese $\left(\geq 30 \mathrm{~kg} / \mathrm{m}^{2}\right),{ }^{17}$ and percentage of FM (according to BOD POD), percentage of total and trunk FM (according to DXA) and FMI as tertiles. Also, four variables were generated classifying individuals according to BMI, total FM, trunk FM, and FMI as follows: none - reference category - (no obese or not in the highest tertile either at 18 or at 22 years), obese or belong to the highest tertile only at 18 years, obese or belong to the highest tertile only at 22 years, and obese or belong to the highest tertile at both ages (18 and 22 years).

Categorical variables were described as absolute and relative frequencies, whereas continuous variables were described by mean and SDs. Crude and adjusted logistic regression and multinomial logistic regression were used to test associations between the outcomes and exposures.

Logistic regression was used for wheezing in the last year and for persistent wheezing, while multinomial regression was used for wheezing and atopy combined (only wheezing, wheezing without atopy, wheezing with atopy, and only atopy); the reference category was those who did not report wheezing and/or atopy. For adjustment, the following covariates were taken into account: sex (male/female), self-reported skin color (white/black/brown/other), asset index (quintiles), years of study (complete years), maternal smoking during pregnancy collected at birth (yes/no), variables that had been gathered at the 11-year follow-up (parents smoking during childhood, parents history of asthma, wheezing or bronchitis, hospitalization during the first 10 years), household crowding (number of house residents) collected at 18 years follow-up; smoking and physical activity at leisure and/or commuting at 18 and 22 years (categorized as none, present only at 18 , present only at 22, and present at both follow-ups). Physical activity was measured through a standardized and previously tested questionnaire (IPAQ) ${ }^{18}$ (categorized as active for $\geq 300$ and 150 minutes a week, according to cutoff points for adolescent and adults, respectively). Confounders were chosen a priori according to previous knowledge and according to the available information on the cohort. Interaction between body composition exposures and sex was tested but it was not significant; therefore, we opted to show results adjusted to sex but nonstratified. Significance level was set as 5\% and all analyses performed using Stata 13.1 software (Stata Corp LP, College Station, TX, USA). 
Interviewers underwent standardization testing before beginning of field work and every 2 months afterward to determine repeatability and validity of weight, height, and skinfold measurements. All cohort follow-up projects were approved by the Federal University of Pelotas Ethics Committee. The protocols for the 18- and 22-year visits were $05 / 11$ and 1.250.366, respectively. The cohort participants, or their caregivers, signed the term of free and informed consent prior to participation and the study was conducted in accordance with the Declaration of Helsinki.

\section{Results}

The response rate of the 1993 Birth Cohort at 11, 15, 18, and 22 years was $87.5 \%, 85.7 \%, 81.4 \%$, and $76.3 \%$, respectively. ${ }^{13}$ The characteristics of the 3,810 members of the 1993 Pelotas Birth cohort followed up when they were 22 years old (Table 1). Most of them had white skin color and around $70 \%$ of them had nine or more years of schooling. Smoking during pregnancy was present in nearly one-third of the mothers and around $40 \%$ among fathers. Hospitalization during childhood was referred by $37 \%$ and family history of asthma, wheezing, or bronchitis by nearly $35 \%$. The number of house residents was six or more people for $17 \%$ of the cohort participants at the 18-year follow-up. At 18 and 22 years, $44 \%$ of them were active and $9.9 \%$ were smokers. Obesity at both ages was $7.8 \%$ and the percentage in the highest tertile of all FM measures and of FMI at 18 and 22 years was similar (around 24.0\%).

Figure 1 shows a prevalence of wheezing in the last 12 months of $10.6 \%$ (95\% CI: 9.6-11.6), without significant difference according to sex $(P=0.130)$ at the age of 22 years, while wheezing without atopy was more prevalent among males $(4.6 \%$; $95 \%$ CI: 3.6-5.6) than females (3.3\%; 95\% CI: $2.5-4.1)(P=0.04)$. The highest prevalence was for the outcome "atopy symptoms" reaching $30.9 \%(95 \% \mathrm{CI}$ : 29.5-32.4) and more frequent among females (34.3\%; $95 \%$ CI: $32.2-36.3)$ than males $(27.1 \%$; 95\% CI: 25.1-29.2). Persistent wheezing, that is, those who have answered yes for wheezing at 18 and at 22 years old, did not differ according to sex (4.0\%; 95\% CI: 3.3-4.6) (data shown as Table S1).

Mean BMI was slightly higher at 22 than at 18 years and similar according to sex. The percentage of FM measured by BOD POD and DXA was higher at 22 compared to 18 years and higher among women than men at both follow-ups; the same pattern was observed for FMI (Table 2).

Obesity and most measures of adiposity were positively associated with wheezing at 22 years (Table 3 ). In the adjusted analysis, for those who were obese at 18 and 22 years or did
Table I Characteristics of the 22-year follow-up sample

\begin{tabular}{|c|c|}
\hline Variables & $\mathbf{N}(\%)$ \\
\hline \multicolumn{2}{|l|}{ Gender } \\
\hline Male & $\mathrm{I}, 783(46.8)$ \\
\hline Female & $2,027(53.2)$ \\
\hline \multicolumn{2}{|l|}{ Skin color } \\
\hline White & $2,262(63.3)$ \\
\hline Black & $538(15.1)$ \\
\hline Brown & $637(17.8)$ \\
\hline Other & $137(3.8)$ \\
\hline \multicolumn{2}{|l|}{ Asset index (quintiles) } \\
\hline First (poorest) & $761(20.0)$ \\
\hline Second & $76 I(20.0)$ \\
\hline Third & $761(20.0)$ \\
\hline Fourth & $76 I(20.0)$ \\
\hline Fifth (richest) & $760(20.0)$ \\
\hline \multicolumn{2}{|l|}{ Education (years) } \\
\hline $0-4$ & III (2.9) \\
\hline $5-8$ & $1,013(26.6)$ \\
\hline $9-11$ & $\mathrm{I}, 560(4 \mathrm{I} .0)$ \\
\hline$\geq 12$ & $\mathrm{I}, \mathrm{I} 2 \mathrm{I}(29.5)$ \\
\hline Maternal smoking during pregnancy & $\mathrm{I}, 242(32.6)$ \\
\hline \multicolumn{2}{|l|}{ Maternal smoking at I I years follow-up } \\
\hline Never & $\mathrm{I}, 693(46.9)$ \\
\hline Former & $787(21.8)$ \\
\hline Smoker & $I,|3|(3 \mid .3)$ \\
\hline \multicolumn{2}{|l|}{$\begin{array}{l}\text { Paternal (or mothers partner) smoking at I I } \\
\text { years follow-up }\end{array}$} \\
\hline Never & $\mathrm{I}, 030(37.2)$ \\
\hline Former & $707(25.5)$ \\
\hline Smoker & $\mathrm{I}, 03 \mathrm{I}(37.3)$ \\
\hline Hospitalization during the first 10 years of life & $1,339(37.1)$ \\
\hline $\begin{array}{l}\text { Parents history of asthma, wheezing, or } \\
\text { bronchitis at II years follow-up }\end{array}$ & $\mathrm{I}, 236(34.8)$ \\
\hline \multicolumn{2}{|l|}{ Household crowding at I 8 years } \\
\hline$\leq 3$ & $1,359(38.6)$ \\
\hline $4-5$ & $1,569(44.5)$ \\
\hline$\geq 6$ & $595(16.9)$ \\
\hline \multicolumn{2}{|l|}{$\begin{array}{l}\text { Active at leisure and/or commuting at } 18 \\
\text { and } 22 \text { years }\end{array}$} \\
\hline None & $648(18.5)$ \\
\hline Only at 18 years & $569(16.2)$ \\
\hline Only at 22 years & $749(21.3)$ \\
\hline Both ages & $\mathrm{I}, 542(44.0)$ \\
\hline \multicolumn{2}{|l|}{ Smoker at 18 and 22 years } \\
\hline None & $2,824(80.3)$ \\
\hline Only at 18 years & $117(3.3)$ \\
\hline Only at 22 years & $229(6.5)$ \\
\hline Both ages & $347(9.9)$ \\
\hline \multicolumn{2}{|l|}{ BMI obese $\left(\geq 30 \mathrm{~kg} / \mathrm{m}^{2}\right)$ at 18 and 22 years } \\
\hline None & $2,689(79.9)$ \\
\hline Only at 18 years & $69(2.1)$ \\
\hline Only at 22 years & $344(10.2)$ \\
\hline Both ages & $262(7.8)$ \\
\hline \multicolumn{2}{|l|}{$\begin{array}{l}\text { Total fat mass - BOD POD } \% \text { in the third } \\
\text { tertile }\end{array}$} \\
\hline None & $\mathrm{I}, 905(58.4)$ \\
\hline Only at 18 years & $302(9.3)$ \\
\hline
\end{tabular}

(Continued) 
Table I (Continued)

\begin{tabular}{|l|l|}
\hline Variables & N (\%) \\
\hline Only at 22 years & $287(8.8)$ \\
Both ages & $770(23.6)$ \\
Total fat mass - DXA \% in the third tertile & \\
None & $1,751(58.7)$ \\
Only at I8 years & $259(8.7)$ \\
Only at 22 years & $270(9.1)$ \\
Both ages & $704(23.6)$ \\
Trunk fat mass - DXA \% in the third tertile & \\
None & $1,741(58.3)$ \\
Only at I8 years & $271(9.1)$ \\
Only at 22 years & $280(9.4)$ \\
Both ages & $697(23.3)$ \\
FMl in the third tertile & \\
None & $\mathrm{I}, 910(58.6)$ \\
Only at I8 years & $273(8.4)$ \\
Only at 22 years & $278(8.5)$ \\
Both ages & $801(24.6)$ \\
\hline
\end{tabular}

Notes: The 1993 Pelotas Birth cohort $(n=3,810)$. Maximum missing values for DXA variables (total $n=3,325$ ).

Abbreviations: BMI, body mass index; DXA, dual-energy X-ray absorptiometry; FMl, fat mass index.

belong to the highest tertile of FM and FMI also at both follow-ups, the odds ratio (OR) for "wheezing" was higher than for those who were not obese or did not belong to the highest tertile of adiposity. Also, the ORs for wheezing in the last 12 months varied from 2.0 (95\% CI: 1.32-3.03), for those who were obese at both follow-ups, to 1.58 (95\% CI: 1.14-2.20) for those belonging to the third tertile of percentage of total FM at both ages.
Very similar results were observed between obesity and measures of adiposity for the outcome "only wheezing without atopy", with the highest ORs for those who had been obese or who belonged to the highest tertile of adiposity at 18 and at 22 years, in the adjusted analysis. Although the OR was 1.59 for wheezing without atopy according to FMI in the adjusted analysis at both follow-ups, the confidence interval included the unit (Table 3). For wheezing plus atopy (outcome shown in the third column of Table 3), there was an association between the highest tertile of total FM measured by DXA and trunk FM (OR of 1.60; 95\% CI: 1.06-2.42; OR of $1.65 ; 95 \% \mathrm{CI}: 1.08-2.51)$ with $P$-values of 0.021 and 0.014 , respectively. For the outcome "only symptoms of atopy", in the adjusted analysis there was a positive and significant association only for the exposure "percentage trunk FM" at both follow-ups (OR=1.26; 95\% CI: 1.0-1.59) (Table 3). Persistent wheezing followed the same pattern as wheezing, with higher OR for those who were obese or in the third tertile of adiposity at both ages (18 and 22 years), although probably due to the sample size the results did not reach statistical significance (Table S1)

\section{Discussion}

This paper describes a positive association between cumulative obesity/adiposity at 18 and 22 years and the phenotype wheezing at 22 years, even after adjustment for confounders; this association seems to be more due to wheezing than to atopy, because the results for the atopic phenotype (alone)

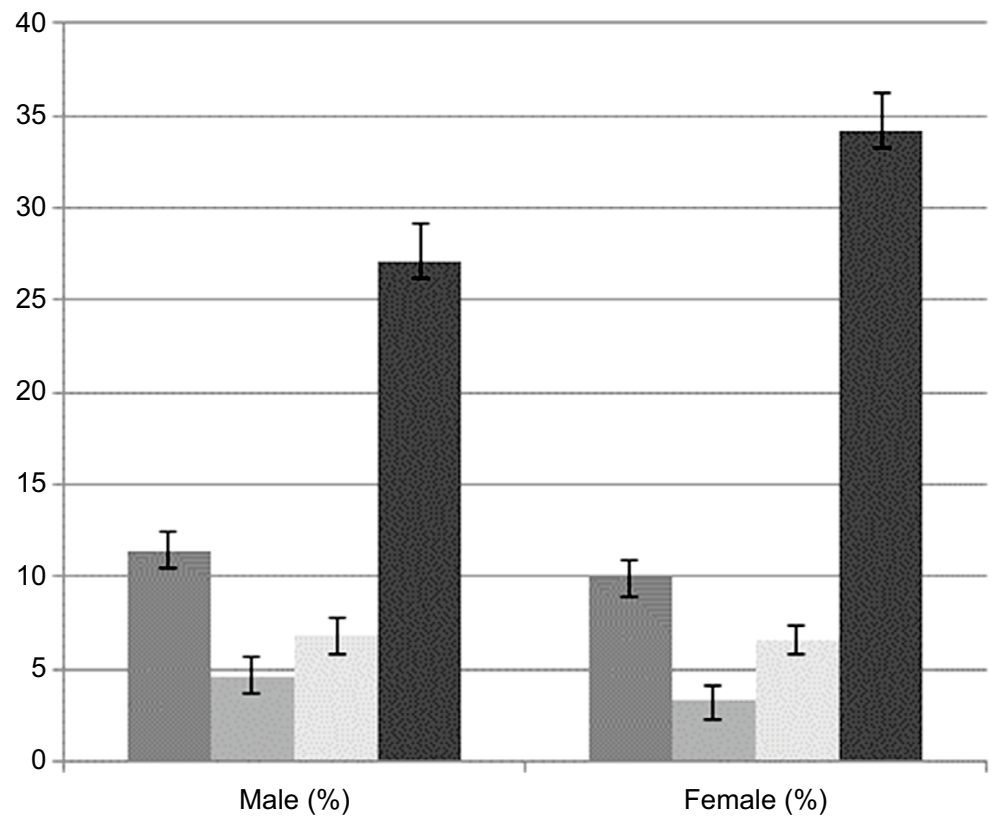

Figure I Prevalence of self-reported wheezing and atopy symptoms in the last 12 months at 22 years by sex. Note: The 1993 Pelotas Birth Cohort.
Total wheezing (with or without atopy)

Wheezing without atopy

Wheezing with atopy

Only atopy 
Table 2 Mean BMI and body composition variables at 18- and 22-year follow-up by sex

\begin{tabular}{|l|l|l|l|l|}
\hline \multicolumn{2}{|l|}{ Variables } & \multicolumn{2}{l|}{ Males } & \multicolumn{2}{l|}{ Females } \\
\cline { 2 - 5 } & $\begin{array}{l}\text { I8 years } \\
\text { Mean (SD) }\end{array}$ & $\begin{array}{l}\text { 22 years } \\
\text { Mean (SD) }\end{array}$ & $\begin{array}{l}\text { I8 years } \\
\text { Mean (SD) }\end{array}$ & $\begin{array}{l}\text { 22 years } \\
\text { Mean (SD) }\end{array}$ \\
\hline BMI $\left(\mathrm{kg} / \mathrm{m}^{2}\right)$ & $23.3(4 . \mathrm{I})$ & $25.1(4.8)$ & $23.5(4.8)$ & $25.6(5.8)$ \\
Total fat mass (BOD POD \%) & $16.7(8.7)$ & $20.9(9.8)$ & $32.8(7.8)$ & $35.8(8.5)$ \\
Total fat mass (DXA \%) & $16.8(9.3)$ & $20.8(10.0)$ & $34.9(8.4)$ & $38.0(8.8)$ \\
Trunk fat mass (DXA \%) & $18.8(10.5)$ & $24.2(11.5)$ & $36.0(9.3)$ & $39.4(9.7)$ \\
FMl (fat kg/height $\left.\mathrm{m}^{2}\right)$ & $4.2(3.0)$ & $5.6(3.7)$ & $8.0(3.6)$ & $9.5(4.4)$ \\
\hline
\end{tabular}

Notes: The 1993 Pelotas Birth Cohort. BMI n=3,588; BOD POD $n=3,559 ;$ DXA $n=3,325$.

Abbreviations: BMI, body mass index; DXA, dual-energy X-ray absorptiometry; FMI, fat mass index..

were not so consistent. Persistence of wheezing at both ages also showed the same pattern as for the phenotype wheezing, although there was absence of statistical significance due to lack of power.

Most of the literature has shown an association between wheezing and obesity; however, few articles have been tried to disentangle the different phenotypes (wheezing and atopy). Classification of phenotypes is important to predict the prognosis and response to treatment and understand its underlying mechanisms. ${ }^{19}$ Epidemiologic studies have considered instability of asthma phenotypes over time $\mathrm{e}^{20,21}$ and identified associated risk factors for each asthma phenotype. ${ }^{19}$ Therefore, the aim of the present study was to evaluate the association of obesity/adiposity considering different phenotypes, such as atopic, nonatopic, and persistent.

It is plausible to think that symptoms of wheezing and atopy are a good proxy for asthma diagnosis, even without methacholine tests, because wheezing is the main symptom of asthma. ${ }^{22,23}$ One can argue this as a limitation of the paper, but at the young age of 18 and 22 years, asthma is the most prevalent chronic noncommunicable disease with wheezing as its main symptom; COPD is an important differential diagnosis from asthma, but COPD usually shows symptoms after the age of 40 years and not at young adulthood and its mains symptoms are cough, sputum, and dyspnea. The wheezing information may suffer from recall bias; however, we applied a well-known validated instrument to measure asthma symptoms, which eases such bias. ${ }^{14,15}$ Atopy in the present paper was based only on symptoms of rhinitis or symptoms of eczema, without skin prick tests or IgE measurement; this is indeed a limitation in the interpretation of the results, although it has been used in several studies. ${ }^{24,25}$

On the other hand, several strengths should be emphasized in this study. The prospective design allowed us to evaluate temporality and the cumulative role of the exposures for the studied outcomes. According to our results, it seems that current exposure (22 years) and cumulative exposure of obesity and adiposity (18 and 22 years) are the main risk factors for the wheezing phenotype at early adulthood, since the highest OR was observed for those subjects obese or with adiposity at two points in time (18 and 22 years) or for those with the exposure at 22 years. The very high attrition rates at all phases of this cohort reassure us of the robustness of the findings. Due to the low refusal rates and to the several follow-ups of this cohort, we were able to adjust for important potential confounders, which could be misleading the findings. Socioeconomic (SE) status is one of the most important confounders in the association between obesity/ adiposity and wheezing and atopy; in this cohort it has been found that wheezing is more prevalent among poor people (12.7\% in the poor tertile of income) than among rich people (9.3\%), at 22 years (data not shown); and the prevalence of atopy shows the opposite pattern, prevalence of 5.6\% among poor and $18.5 \%$ among rich, at the same age. Similar finding was observed in a historical cohort from Glasgow at adolescence and young adulthood age (16-30 years $)^{26}$; they evaluated the effect of SE position based on several indicators and wheezing and atopy and it has been found that a low SE position was associated with wheezing and a high SE position was associated with atopy. Other study with the Avon Longitudinal Study of Parents and Children (ALSPAC) cohort at childhood (7-8 years) found an association between wheezing with low SE status and atopy with high SE status. ${ }^{27}$

Most studies have evaluated obesity only by BMI; however, BMI alone may not adequately characterize the relation between overweight or obesity and complex diseases such as asthma. ${ }^{3}$ For instance, its usefulness and predictive value have been questioned in studies of cardiovascular disease and diabetes. ${ }^{28,29}$ Adiposity measured by highly precise methods (BOD POD and DXA) - as it was performed in the present cohort - enabled us to analyze the \% of FM and the FMI, which are better measures of adiposity than BMI., ${ }^{9,10}$ 


\begin{tabular}{|c|c|c|c|c|c|c|c|c|}
\hline \multirow{2}{*}{ 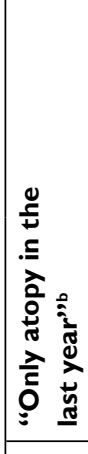 } & 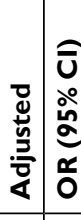 & 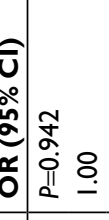 & 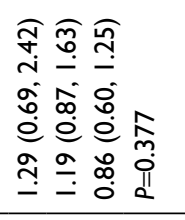 & 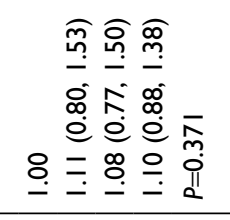 & 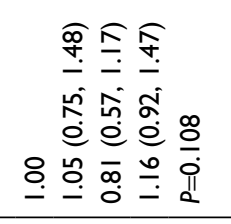 & 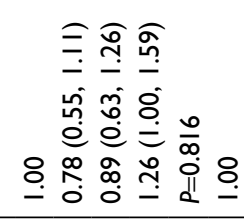 & 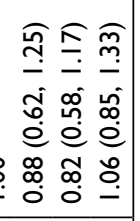 & 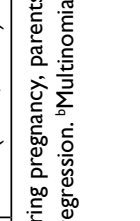 \\
\hline & 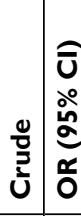 & 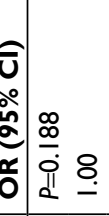 & 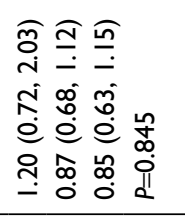 & 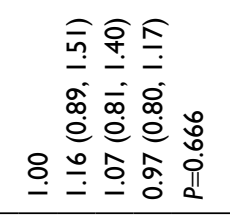 & 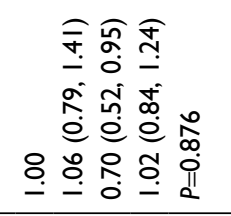 & 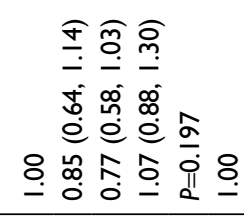 & 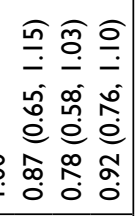 & 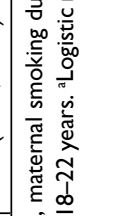 \\
\hline \multirow{2}{*}{ 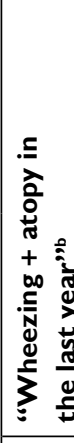 } & 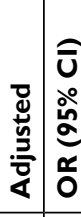 & & 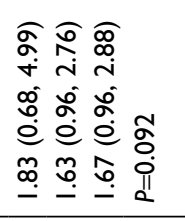 & 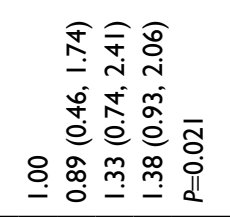 & 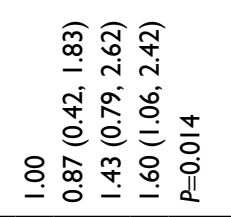 & 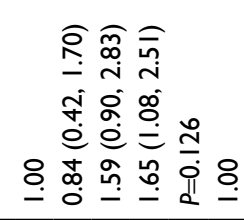 & 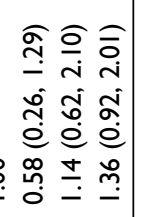 & 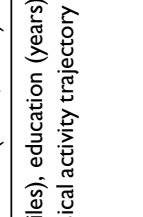 \\
\hline & 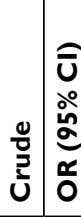 & & 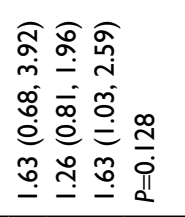 & 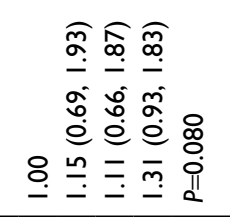 & 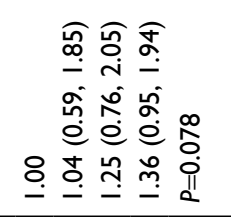 & 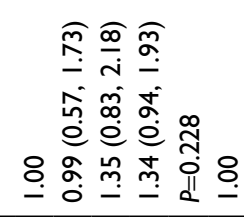 & 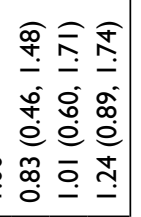 & 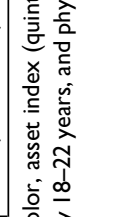 \\
\hline \multirow{2}{*}{ 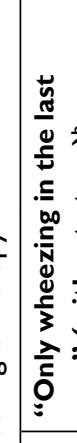 } & 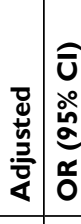 & 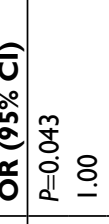 & 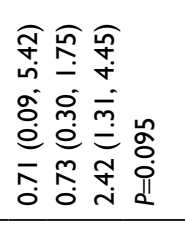 & 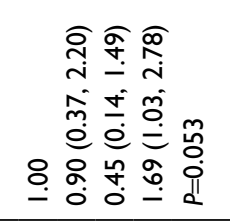 & 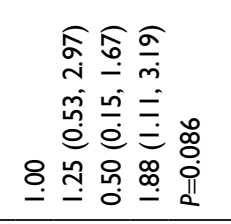 & 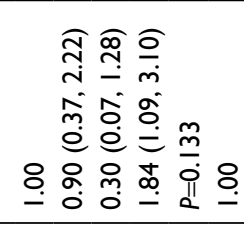 & 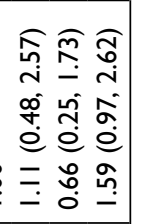 & 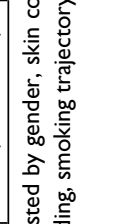 \\
\hline & & 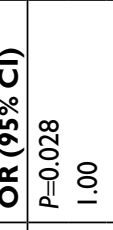 & 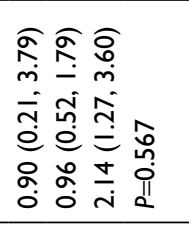 & 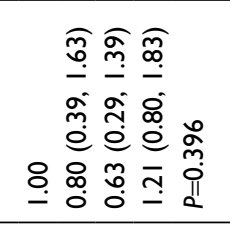 & 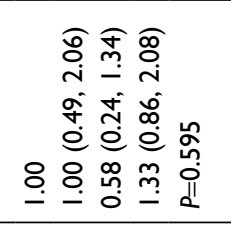 & 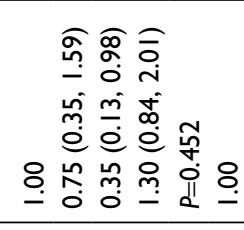 & 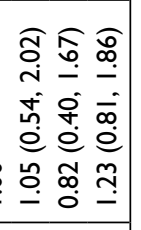 & 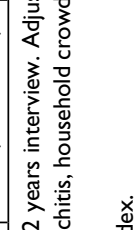 \\
\hline \multirow{3}{*}{ 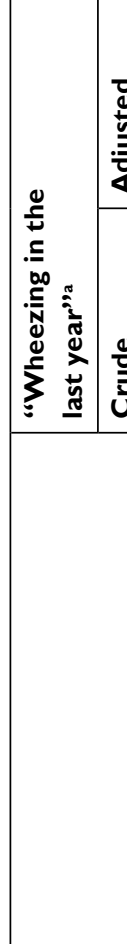 } & 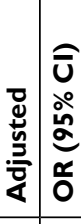 & 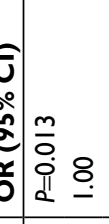 & 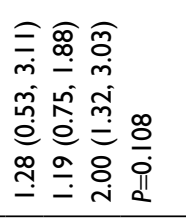 & 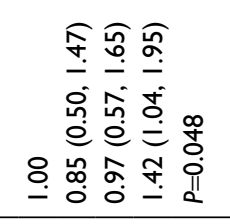 & 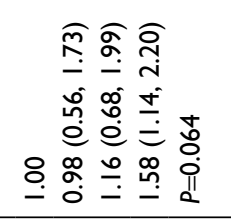 & 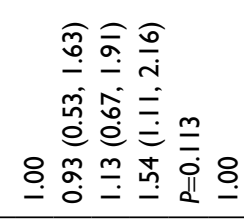 & 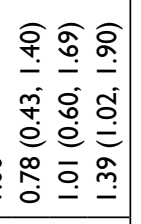 & 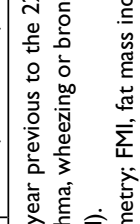 \\
\hline & & 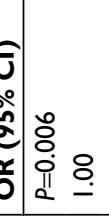 & 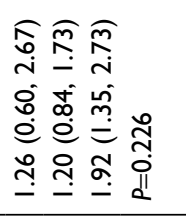 & 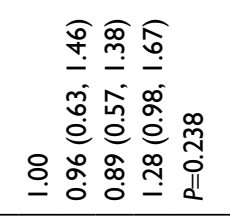 & 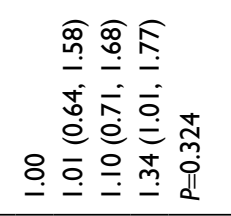 & 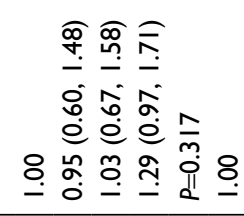 & 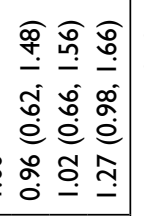 & 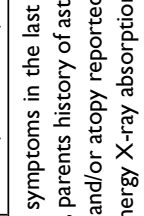 \\
\hline & & 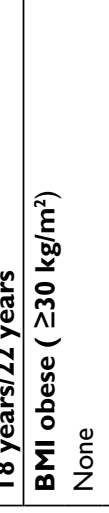 & 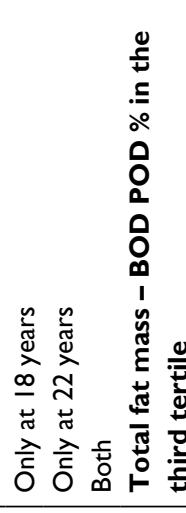 & 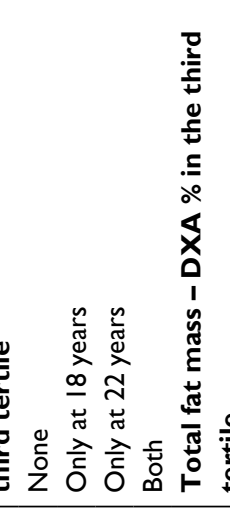 & 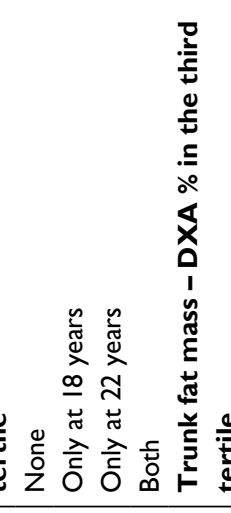 & 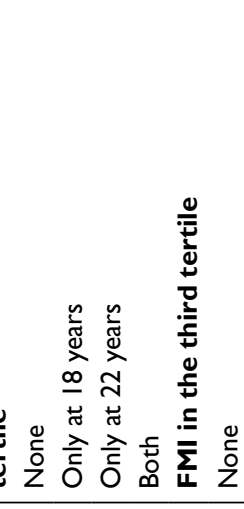 & 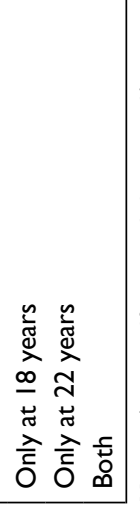 & 2 \\
\hline
\end{tabular}


A very interesting study from a developed country (England) investigated whether the magnitude of the obesity/ adiposity effect varied when asthma was classified as atopic and nonatopic; the study was based on the ALSPAC cohort at the age of 7-9 years, with measures of FM obtained by DXA. ${ }^{4}$ Using a Mendelian randomization approach, the authors observed a stronger effect of obesity/adiposity for nonatopic children (relative ratio [RR]: 1.90, 95\% CI: 1.19-3.03) than for atopic according to BMI (RR: 1.37, 95\% CI: 0.89-2.11) and according to FM an RR of 1.73 (95\% CI: 1.17-2.55) and 1.25 (95\% CI: 0.86-1.80), respectively.

Noal et al using data from the 1993 Birth Cohort from Pelotas found a positive association between wheezing and obesity measured by BMI and skinfolds during adolescence. ${ }^{1}$ The highest $R R$ was found for prevalence of wheezing among those who had been obese at two follow-ups (11 and 15 years) with an adjusted RR of 1.44 (95\% CI: 1.01-2.07); for those ever in the highest tertile of skinfolds trajectory from 11 to 15 years the adjusted RR was 1.34 (95\% CI: 0.94-1.92); they also found an association between the same exposure categories and persistent wheezing (present at 11 and 15 years). The results of the analysis at 18 and 22 years in the Pelotas cohort reveal the same pattern of results as it had been observed at the beginning of adolescence; besides that, we have shown this association classifying the sample on the nonatopic (wheezing) and atopic phenotypes, and using a more accurate measure of adiposity such as BOD POD and DXA.

Similar results to our findings were also observed in the NHANES population (2-19 years), although they have measured obesity only by BMI; among nonatopic children and adolescents the OR for wheezing was 2.20 (95\% CI: 1.15-4.22) and for atopic population there was not greater risk for those obese compared to nonobese. ${ }^{2}$

In a population-based study in Puerto Rican children (6-14 years), the authors found that adiposity indicators were associated with asthma, severity of asthma, and atopy, and they concluded that atopy was a mediator in this association through the mediation analysis ${ }^{3}$; the main limitation of this study was the cross-sectional design and the possibility of reverse causation since temporality could not be ascertained.

Some studies have shown an association between persistence or severity of asthma (atopic and nonatopic) and obesity; Noal et al found a positive association in the same cohort as the present one, at 11 and 15 years; the outcome was "wheezing in the last 12 months" (not specifically atopic and nonatopic); an RR of 1.79 (95\% CI: $1.20-2.68)$ and 1.82 (95\% CI: 1.10-3.02) for those adolescents obese and for those in the highest tertile of skinfolds at 11 and 15 years, respectively. ${ }^{1}$ In the NHANES study they found an OR of 2.14, although without statistical significance, from those who have had more medical visits due to wheezing among nonatopic than the atopic asthmatics (OR=1.10; 95\% CI: 0.60-2.00). ${ }^{3}$ We subclassified the persistent wheezing phenotype in those only with "persistent wheezing" (without atopy) and those with "persistent wheezing and atopy" and we did not observe differences among these two phenotypes and obesity/adiposity (data not shown).

Several plausible mechanisms have been proposed to explain the relationship between obesity/adiposity and asthma, including enhanced systemic inflammation. ${ }^{30,31}$ Results from the NHANES study evaluating CRP suggest that overweight may indeed lead to systemic inflammation that in turn leads to an increased risk of asthma in nonatopic individuals. There was no evidence of this relationship between systemic inflammation and asthma among atopic youth according to NHANES data. These findings suggest that allergic and systemic inflammation may operate independently on the pathway to asthma. ${ }^{2}$

Another possible link would be through promotion of allergic inflammation by adipokine effects on the immune system, ${ }^{32}$ but our results and also those from other studies showing stronger associations of obesity with nonatopic, ${ }^{4}$ and no evidence that obesity is associated with atopy, lead us to conclude that the role of inflammation in the different phenotypes is currently unclear. We performed some analysis to see whether IL-6 and PCR were associated with atopic or nonatopic asthma in our cohort and we found a higher OR for a mean IL-6 in the third tertile at 18 and at 22 years for the phenotype wheezing and not for atopy, although most of the results were not statically significant; the OR for IL-6 and for CRP with atopy was protective (data not shown).

Given conflicting findings from studies of overweight or obesity (largely assessed by BMI) and atopy or nonatopic diseases, the role of inflammation in the different phenotypes is currently unclear. ${ }^{2,33-35}$

As the prevalence of obesity and asthma has been increasing over the last years in LA, and to the conflicting results of the association between the different phenotypes (atopic and nonatopic asthma) and obesity/adiposity, we suggest more studies to be carried out with a prospective design and using precise methods for measuring atopy and adiposity.

\section{Conclusion}

There is a positive longitudinal association between cumulative obesity and adiposity at 18 and 22 years and wheezing at 22 years, even after adjustment for confounders; this association seems to be more due to wheezing than atopy, because the results for atopy were not so consistent. 


\section{Acknowledgments}

The 1993 Birth Cohort study is currently supported by the Wellcome Trust through the programme entitled Major Awards for Latin America on Health Consequences of Population Change. The European Union, National Support Program for Centers of Excellence (PRONEX), the Brazilian National Research Council (CNPq), the Foundation for Research Support of the State of Rio Grande do Sul (FAPERGS), Coordenação de Aperfeiçoamento de Pessoal de Nível Superior (CAPES -Finance Code 001), and the Brazilian Ministry of Health supported phases of the study.

\section{Disclosure}

The authors report no conflicts of interest in this work.

\section{References}

1. Noal RB, Menezes AM, Macedo SE, et al. Is obesity a risk factor for wheezing among adolescents? A prospective study in southern Brazil. J Adolesc Health. 2012;51(6 Suppl):S38-S45.

2. Visness CM, London SJ, Daniels JL, et al. Association of childhood obesity with atopic and nonatopic asthma: results from the National Health and Nutrition Examination Survey 1999-2006. JAsthma. 2010;47(7):822-829.

3. Forno E, Acosta-Pérez E, Brehm JM, et al. Obesity and adiposity indicators, asthma, and atopy in Puerto Rican children. J Allergy Clin Immunol. 2014;133(5):1308-1314, 1314.e1-5.

4. Granell R, Henderson AJ, Evans DM, et al. Effects of BMI, fat mass, and lean mass on asthma in childhood: a Mendelian randomization study. PLoS Med. 2014;11(7):e1001669.

5. Noal RB, Menezes AM, Macedo SE, Dumith SC. Childhood body mass index and risk of asthma in adolescence: a systematic review. Obes Rev. 2011;12(2):93-104.

6. Mebrahtu TF, Feltbower RG, Greenwood DC, Parslow RC. Childhood body mass index and wheezing disorders: a systematic review and meta-analysis. Pediatr Allergy Immunol. 2015;26(1):62-72.

7. Beuther DA, Sutherland ER. Overweight, obesity, and incident asthma: a meta-analysis of prospective epidemiologic studies. Am J Respir Crit Care Med. 2007;175(7):661-666.

8. Strina A, Barreto ML, Cooper PJ, Rodrigues LC. Risk factors for nonatopic asthma/wheeze in children and adolescents: a systematic review. Emerg Themes Epidemiol. 2014;11:5.

9. Gonzalez MC, Correia M, Heymsfield SB. A requiem for BMI in the clinical setting. Curr Opin Clin Nutr Metab Care. 2017;20(5):314-321.

10. Müller MJ, Braun W, Enderle J, Bosy-Westphal A. Beyond BMI: conceptual issues related to overweight and obese patients. Obes Facts. 2016;9(3):193-205.

11. de Magalhães Simões S, da Cunha SS, Cruz ÁA, et al. A community study of factors related to poorly controlled asthma among Brazilian urban children. PLoS One. 2012;7(5):e37050.

12. Victora CG, Barros FC, Halpern R, et al. Estudo longitudinal da população materno-infantil da região urbana do Sul do Brasil, 1993: aspectos metodológicos e resultados preliminares. [Longitudinal study of the mother and child population in an urban region of southern Brazil, 1993: methodological aspects and preliminary results]. Rev Saude Publica. 1996;30(1):34-45. Portuguese.

13. Gonçalves H, Wehrmeister FC, Assunção MCF, et al. Cohort profile update: the 1993 Pelotas (Brazil) Birth Cohort follow-up at 22 years. Int J Epidemiol. 2018;47(5):1389-1390e.

14. Solé D, Vanna AT, Yamada E, Rizzo MC, Naspitz CK. International Study of Asthma and Allergies in Childhood (ISAAC) written questionnaire: validation of the asthma component among Brazilian children. J Investig Allergol Clin Immunol. 1998;8(6):376-382.
15. Asher MI, Weiland SK. The International Study of Asthma and Allergies in Childhood (ISAAC). ISAAC Steering Committee. Clin Exp Allergy $J$ Br Soc Allergy Clin Immunol. 1998;28(Suppl 5):52-66; discussion 90-91.

16. Fields DA, Goran MI, McCrory MA. Body-composition assessment via air-displacement plethysmography in adults and children: a review. $\mathrm{Am}$ J Clin Nutr. 2002;75(3):453-467.

17. de Onis M, Onyango AW, Borghi E, Siyam A, Nishida C, Siekmann J. Development of a WHO growth reference for school-aged children and adolescents. Bull World Health Organ. 2007;85(9):660-667.

18. Bastos JP, Araujo CL, Hallal PC. Prevalence of insufficient physical activity and associated factors in Brazilian adolescents. $J$ Phys Act Health. 2008;5(6):777-794.

19. Lee E, Lee SH, Kwon JW, et al. Persistent asthma phenotype related with late-onset, high atopy, and low socioeconomic status in school-aged Korean children. BMC Pulm Med. 2017;17(1):45.

20. Green RH, Pavord I. Stability of inflammatory phenotypes in asthma. Thorax. 2012;67(8):665-667.

21. Sorkness RL, Zoratti EM, Kattan M, et al. Obstruction phenotype as a predictor of asthma severity and instability in children. J Allergy Clin Immunol. 2018;142(4):1090-1099.e4.

22. Kurukulaaratchy RJ, Fenn M, Matthews S, Arshad SH. Characterisation of atopic and non-atopic wheeze in 10 year old children. Thorax. 2004;59(7):563-568

23. Court CS, Cook DG, Strachan DP. Comparative epidemiology of atopic and non-atopic wheeze and diagnosed asthma in a national sample of English adults. Thorax. 2002;57(11):951-957.

24. Wu CC, Chen RF, Kuo HC. Different implications of paternal and maternal atopy for perinatal IgE production and asthma development. Clin Dev Immunol. 2012;2012:132142.

25. Platts-Mills TA. The role of immunoglobulin E in allergy and asthma. Am J Respir Crit Care Med. 2001;164(8 Pt 2):S1-S5.

26. Patel S, Henderson J, Jeffreys M, Davey Smith G, Galobardes B. Associations between socioeconomic position and asthma: findings from a historical cohort. Eur J Epidemiol. 2012;27(8):623-631.

27. Galobardes B, Granell R, Sterne J, et al. Childhood wheezing, asthma, allergy, atopy, and lung function: different socioeconomic patterns for different phenotypes. Am J Epidemiol. 2015;182(9):763-774.

28. Kodama S, Horikawa C, Fujihara K, et al. Comparisons of the strength of associations with future type 2 diabetes risk among anthropometric obesity indicators, including waist-to-height ratio: a meta-analysis. $\mathrm{Am}$ J Epidemiol. 2012;176(11):959-969.

29. Chrysant SG, Chrysant GS. New insights into the true nature of the obesity paradox and the lower cardiovascular risk. JAm Soc Hypertens. 2013;7(1):85-94.

30. Ford ES, Galuska DA, Gillespie C, Will JC, Giles WH, Dietz WH. C-reactive protein and body mass index in children: findings from the Third National Health and Nutrition Examination Survey, 1988-1994. J Pediatr. 2001;138(4):486-492.

31. Retnakaran R, Hanley AJ, Connelly PW, Harris SB, Zinman B. Elevated C-reactive protein in Native Canadian children: an ominous early complication of childhood obesity. Diabetes Obes Metab. 2006;8(5):483-491.

32. Fenger RV, Gonzalez-Quintela A, Vidal C, et al. Exploring the obesityasthma link: do all types of adiposity increase the risk of asthma? Clin Exp Allergy. 2012;42(8):1237-1245.

33. Cibella F, Cuttitta G, La Grutta S, Melis MR, Bucchieri S, Viegi G. A cross-sectional study assessing the relationship between BMI, asthma, atopy, and eNO among schoolchildren. Ann Allergy Asthma Immunol. 2011;107(4):330-336.

34. Hancox RJ, Milne BJ, Poulton R, et al. Sex differences in the relation between body mass index and asthma and atopy in a birth cohort. $A m$ $J$ Respir Crit Care Med. 2005;171(5):440-445.

35. van Gysel D, Govaere E, Verhamme K, Doli E, de Baets F. Body mass index in Belgian schoolchildren and its relationship with sensitization and allergic symptoms. Pediatr Allergy Immunol. 2009;20(3):246-253. 


\section{Supplementary material}

Table SI Association between persistent wheezing and body composition at 18 and 22 years

\begin{tabular}{|c|c|c|}
\hline & Persistent whe & ars/with or without atopy) ${ }^{a}$ \\
\hline & Crude & Adjusted \\
\hline 18 years $/ 22$ years & OR $(95 \% \mathrm{Cl})$ & OR $(95 \% \mathrm{Cl})$ \\
\hline BMI obese $\left(\geq 30 \mathrm{~kg} / \mathrm{m}^{2}\right)$ & $P=0.4 \mid 3$ & $P=0.671$ \\
\hline None & 1.00 & 1.00 \\
\hline Only at 18 years & I.II $(0.34,3.57)$ & $1.50(0.44,5.05)$ \\
\hline Only at 22 years & $0.74(0.37,1.48)$ & $0.77(0.36,1.64)$ \\
\hline Both & $1.50(0.86,2.6 \mathrm{I})$ & $\mathrm{I} .28(0.66,2.5 \mathrm{I})$ \\
\hline Total fat mass - BOD POD $\%$ in the third tertile & $P=0.923$ & $P=0.937$ \\
\hline None & 1.00 & 1.00 \\
\hline Only at 18 years & I.II $(0.61,2.02)$ & $0.93(0.43,2.03)$ \\
\hline Only at 22 years & $0.88(0.45,1.73)$ & I. $18(0.57,2.46)$ \\
\hline Both & $1.10(0.72,1.66)$ & $1.12(0.68,1.83)$ \\
\hline Total fat mass - DXA \% in the third tertile & $P=0.810$ & $P=0.645$ \\
\hline None & 1.00 & 1.00 \\
\hline Only at 18 years & $1.15(0.60,2.22)$ & $0.99(0.43,2.26)$ \\
\hline Only at 22 years & $0.89(0.44, I .8 I)$ & $0.89(0.37,2.15)$ \\
\hline Both & $1.20(0.77,1.85)$ & $1.35(0.82,2.22)$ \\
\hline Trunk fat mass - DXA \% in the third tertile & $P=0.764$ & $P=0.472$ \\
\hline None & 1.00 & 1.00 \\
\hline Only at 18 years & $1.26(0.67,2.37)$ & $1.02(0.45,2.34)$ \\
\hline Only at 22 years & $1.21(0.64,2.28)$ & $1.39(0.66,2.93)$ \\
\hline Both & $1.22(0.78,1.90)$ & $1.46(0.88,2.42)$ \\
\hline FMI in the third tertile & $P=0.828$ & $P=0.905$ \\
\hline None & 1.00 & 1.00 \\
\hline Only at 18 years & $1.21(0.66,2.22)$ & $1.08(0.50,2.32)$ \\
\hline Only at 22 years & $0.81(0.40,1.63)$ & $0.84(0.37,1.90)$ \\
\hline Both & $1.04(0.68,1.58)$ & $\mathrm{I} .14(0.70,1.84)$ \\
\hline
\end{tabular}

Notes: The 1993 Pelotas Birth Cohort. aLogistic regression (persistent wheezing: wheezing in the last 12 months reported at I8- and 22-year follow-ups - yes/no). Adjusted by gender, skin color, asset index (quintiles), education (years), maternal smoking during pregnancy, parents smoking during infancy, hospitalization during infancy, parents history of asthma, wheezing or bronchitis, household crowding, smoking trajectory 18-22 years, and physical activity trajectory 18-22 years.

Abbreviations: BMI, body mass index; DXA, dualenergy X-ray absorptiometry; FMI, fat mass index.

Journal of Asthma and Allergy

\section{Publish your work in this journal}

The Journal of Asthma and Allergy is an international, peer-reviewed open access journal publishing original research, reports, editorials and commentaries on the following topics: Asthma; Pulmonary physiology; Asthma related clinical health; Clinical immunology and the immunological basis of disease; Pharmacological interventions and

\section{Dovepress}

new therapies. This journal is included in PubMed. The manuscript management system is completely online and includes a very quick and fair peer-review system, which is all easy to use. Visit http://www. dovepress.com/testimonials.php to read real quotes from published authors. 